\title{
PEMBERDAYAAN MAHASISWA DENGAN MASYARAKAT DESA BINAI DAN DESA PURA SAJAU KABUPATEN BULUNGAN MELALUI REVOLUSI MENTAL MEWUJUDKAN DESA BERSIH DAN MANDIRI
}

\author{
Empowering Students With The Community Of Binai Village And Pura Sajau In Bulungan \\ Village Through The Mental Revolution To Create A Clean And Independent Village \\ Widyastuti Cahyaningrum $^{1^{*}}$, Budi Hasyim² \\ ${ }^{1,2}$ Fakultas Ekonomi Universitas Borneo Tarakan, Jl. Amal Lama, Tarakan \\ *e-mail korespondensi: widyairawan77@gmail.com
}

\begin{abstract}
ABSTRAK
PKM ini bertujuan untuk upaya rekomendasi pemerintah akan potensi yang dimiliki daerah Kalimantan Utara, sehingga dapat membantu dalam pengelolaan potensi tersebut. Metode yang digunakan adalah parsipatoris. Fokus kegiatan pengabdian pada Desa Binai dan Desa Pura Sajau. Kegiatan Program Kemitraan Masyarakat berbasis Revolusi mental dengan gerakan Indonesia Bersih dan Gerakan Indonesia Mandiri di Desa Binai dan Desa Pura Sajau Kecamatan Tanjung Palas Timur Kabupaten Bulungan berjalan dengan baik.
\end{abstract}

Kata Kunci: Desa Bersih, Desa Mandiri, Revolusi Mental

\section{ABSTRACT}

The PKM was aimed recommend government efforts on the potential of North Kalimantan, so it can assist in managing that potential. The method used is parsipatoris. The focus of devotion activities in Binai and Pura Sajau villages. Community Partnership Program Activities based on the mental revolution with the Movement of Clean Indonesia and Indonesia Independent Movement in Binai Village and Pura Sajau Village Tanjung Palas Utara Subdistrict Bulunga District runs well.

Keywords: Clean Village, Independent Village, Mental Revolution

\section{PENDAHULUAN}

Provinsi Kalimantan Utara terletak di paling utara Pulau Kalimantan dan sekaligus merupakan wilayah perbatasan dengan Negara Malaysia. Jumlah Penduduk Kalimantan Utara sebesar 618.208 jiwa pada tahun 2014, jumlah sumber daya manusia yang belum memadai untuk melakukan pengelolaan dan pengembangan potensi daerah. Salah daerah yang belum memadai dalam pemberdayaan sumberdaya manusia yaitu Kabupaten Bulungan.
Permasalahan pembangunan Kabupaten Bulungan pada dasarnya merupakan kesenjangan harapan (gap expectation) antara kinerja pembangunan yang telah dicapai saat ini dengan yang direncanakan. Secara umum, kesenjangan harapan yang menjadi permasalahan pembangunan di Kabupaten Bulungan disebabkan oleh beberapa hal sebagai berikut: (1) belum dapat mengoptimalkan kekuatan yang dimiliki; (2) belum mampu mengatasi kelemahan-kelemahan yang dimiliki; (3) 
belum maksimal dalam memanfaatkan peluang; dan (4) belum mampu mengatisipasi ancaman.

Kecamatan Tanjung Palas Timur memiliki 8 desa yang diantaranya Desa Tanah Kuning, Desa Mangkupadi, Desa Sajau Pungit, Desa Wonomulyo, Desa Tanjung Agung, Desa Binai, Desa Pura Sajau dan Desa Sajau Hilir. Komoditi khas merupakan salahsatu daerah penghasil ikan (kering/basah), ikan teri, udang, singkong dan kelapa. Sedangkan tanaman holtikultura diantaranya cabai dan tanaman buah-buahan juga mengalami penurunan produksi. Dengan kebun/sawah non irigasi maka sudah dapat di pastikan bahwa hanya dapat menghasilkan produksi ketika musim hujan saja, sementara ketika musim kemarau lahan yang ada di biarkan dan tidak diolah, dengan permasalahan tersebut diperlukan kemandiPura Sajau pertanian yang kelola dengan baik. Dari potensi lokal desa seperti Binai dan Pura Sajau merupakan salah satu desa budaya lokal yang masih memegang teguh dengan adat istiadat dan kearifan lokal serta sejarah yang belum tertata ketertiban dan banyak dikenal secara umum, sehingga menjadi potensi untuk dikembangkan. Selain potensi adat budaya, Desa Binai dan Pura Sajau juga memiliki wisata alam seperti Air terjun potensi lokal untuk menjadi ekowisata belum tertata kebersihannya dan promosi yang kedepannya dapat membangun kemandiPura Sajau serta meningkatkan perekonomian desa. Untuk mewujudkan pemecahan permasalahan tersebut diperlukan suatu penataan dengan gerakan aksi nyata
Bersih, Tertib dan Mandiri berbasis Revolusi Mental.

Dimana revolusi mental diharapkan dapat menjadi salah satu solusi dan ajakan mengubah cara pandang, pikiran, sikap perilaku yang berorientasi pada kemajuan dan kemodernan, sehingga Kabupaten Bulungan dan khususnya Kecamatan Tanjung Palas Timur menjadi mampu berkompetisi menghadapi MEA. Hal ini juga sesuai misi Kabupaten Bulungan yaitu "1) mewujudkan Kabupaten Bulungan sebagai salah satu pusat pangan nasional; 2) mewujudkan industri berbasis masyarakat yang berdaya saing tinggi; 3) meningkatkan aksesibilitas infrastruktur dalam upaya mendorong percepatan pembangunan ekonomi rakyat, inventasi daerah, wilayah pedalaman dan terpencil serta pemerataan pembangunan antar wilayah; 4) pemantapan kualitas SDM; 5) mewujudkan kualitas hidup masyarakat yang tinggi, maju dan sejahtera dan 6) reformasi birokrasi dan revitalisasi lembaga-lembaga pemerintahan menuju tata pemerintahan yang bersih, transparan dan profesional serta berorientasi pada pelayanan publik."

\section{METODE}

Metode Pelaksanaan kegiatan Program kemintraan masyarakat (PKM) terbagi beberapa tahap:

a. Persiapan

PKM ini melibatkan mahasiswa dan masyarakat. Mengkomunikasikan program PKM dengan pemerintah daerah setempat, serta mitra lainnya dengan cara sosialisasi dan 
pendampingan kepada masyarakat. Membuat persetujuan dari kesepakatan kerjasama dengan Badan Pemberdayaan Masyarakat Desa (BPMD) Kabupaten Bulungan.

b. Pelaksanaan Pengabdian Kepada Masyarakat (PKM).

Kegiatan akan dilaksanakan menggunakan metode partisipatoris. Jadi, pelaksanaan program dilakukan dengan melibatkan masyarakat setempat dan mahasiswa KKN sebagai fasilitator. Untuk itu, diperlukan pendampingan dalam setiap kegiatan agar dapat diketahui dinamika dari setiap kegiatan sehingga dapat mewujudkan tujuan pemberdayaan. Adapun kegiatan yang di rancang adalah: (1) Pendampingan/Penyuluhan berupa aktivitas kegiatan Pertanian mahasiswa bersama masyarakat; (2) Aktivitas pendukung lainnya dalam rangka mengembangkan Kesadaran kebersihan, kesehatan dan lingkungan serta nasionalisme dengan program Gerakan Indonesia melayani dan Gerakan Indonesia Mandiri.

c. Rencana Keberlanjutan Program

Kegiatan Peningkatan kapasitas masyarakat di Desa Binai dan Desa Pura Sajau di Kabupaten Bulungan Provinsi Kalimantan Utara ini dapat dengan memasukannya kegiatan pengabdian pada masyarakat yang dilakukan melalui kegiatan Program kemintraan masyarakat (PKM), sehingga dapat mengoptimalkan potensi mahasiswa setiap tahunnya. Melalui program pertanian, setelah implementasi program PKM terlaksana, diharapkan masyarakat wilayah Kabupaten Bulungan lebih mandiri dalam mengolah potensi lokal yang ada, sehingga hasilnya lebih optimal. Selain itu, program ini juga diharapkan dapat membuat masyarakat menjadi lebih cerdas dan kaya akan ilmu yang menunjang pengolah potensi tersebut dan dapat mewujudkan kesejahteraan. Program kedua, peningkatan sumber daya manusia dalam bidang pendidikan dan kesehatan.

Program di bidang pendidikan ini diharapkan dapat meningkatan kesadaran akan pendidikan dan minat membaca pada generasi penerus sehingga dapat membuka wawasan dan ilmu pengetahuan. Sementara dalam bidang kesehatan, masyarakat diharapkan dapat meningkatan kesadaran akan pentingnya kesehatan. Dengan program peningkatan kualitas lingkungan, masyarakat diharapkan dapat lebih bertanggung jawab dalam pemeliharan lingkungan. Program terakhir yaitu pemetaan potensi lokal yang ada agar dapat menjadi refrensi dalam pembangunan desa.

\section{HASIL DAN PEMBAHASAN}

Gerakan Indonesia Bersih (GIB) Program ini fokus pada peningkatan perilaku hidup bersih dan sehat lingkungan keluarga, satuan pendidikan, satuan kerja, dan komunitas, peningkatan sinergi penyediaan sarana dan prasarana yang menunjang perilaku hidup bersih dan sehat. Kebersihan lingkungan dapat berawal dari siapapun termasuk dari lingkungan rumah sendiri. 
Gerakan Indonesia Melayani dengan membuat papan pengumuman kantor desa agar Aparat desa dapat menampilkan infomasi untuk masyarakat secara tertulis. Membuat informasi publik tentang akta kelahiran supaya masyarakat mengetahui tata cara pembuatan akta kelahiran. Sosialisasi gerakan cerdas menggunakan obat yang bertujuan supaya masyarakat desa mengetahui pentingnya mengkonsumsi obat yang tepat dan benar. Gerakan Indonesia Bersih (GIB) Program ini fokus pada peningkatan perilaku hidup bersih dan sehat lingkungan keluarga, satuan pendidikan, satuan kerja, dan komunitas, peningkatan sinergi penyediaan sarana dan prasarana yang menunjang perilaku hidup bersih dan sehat. Kebersihan lingkungan dapat berawal dari siapapun termasuk dari lingkungan rumah sendiri. Seperti halnya kegiatan pengabdian masyarakat yang dilakukan di Desa Binai dan Desa Pura Sajau Kecamatan Tanjung Palas Timur Kabupaten Bulungan.

Kegiatan meliputi pengadaan tempat sampah di sekitar lingkungan desa, Pembuatan dan sosialisasi tanaman Toga, Pengecatan Fasilitas umum yang terlihat kumuh, Pembuatan MOL, dan program kerja bakti. Gerakan Indonesia Tertib program ini fokus pada membiasakan hidup tertib dan teratur dalam bermasyarakat. Adapun program kegiatan yang dilakukan adalah pemasangan stiker tentang pentingnya budaya antri dan tertib dalam berlalu lintas dijalanan yang mana akan memberikan manfaat sebagai infomrasi bagi masyarakat pentingnya hidup tertib dan tertaur ditempat dan fasilitas umum.
Berikut ini kegiatan dokumentasi gerakan Indonesia bersih Desa Binai dan Desa Pura Sajau Kecamatan Tanjung Palas Timur Kabupaten Bulungan.

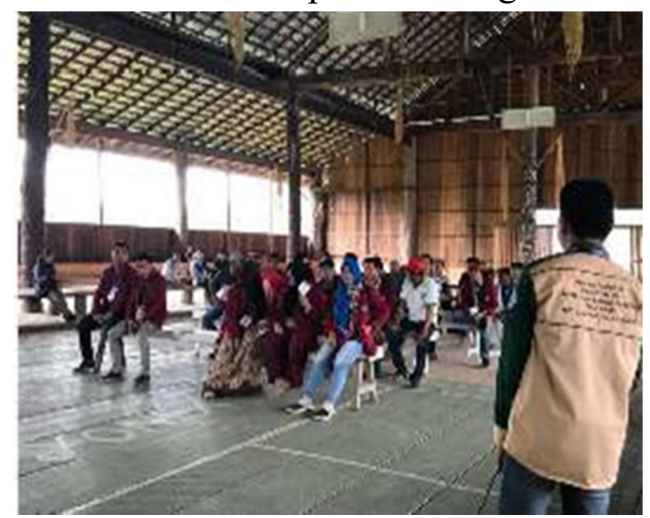

Gambar 1. Sosialiasasi Pembuatan Pupuk MOL (Micro Organisme Lokal) dan Pestisida Nabati

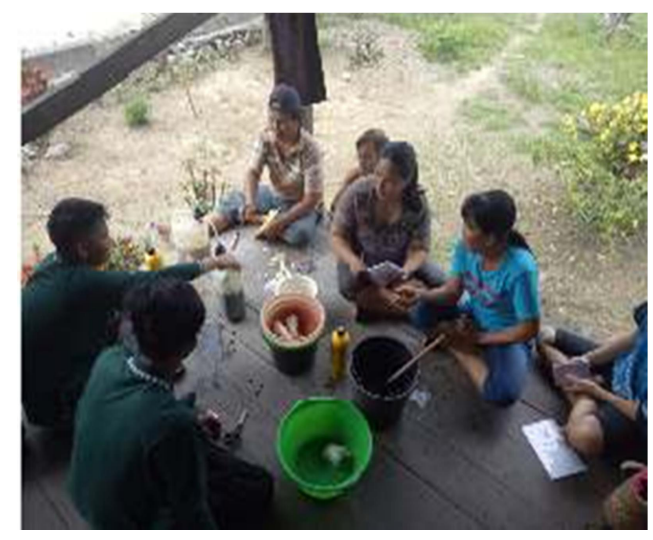

Gambar 2. Praktek Pembuatan Pupuk MOL (Micro Organisme Lokal) dan Pestisida Nabati

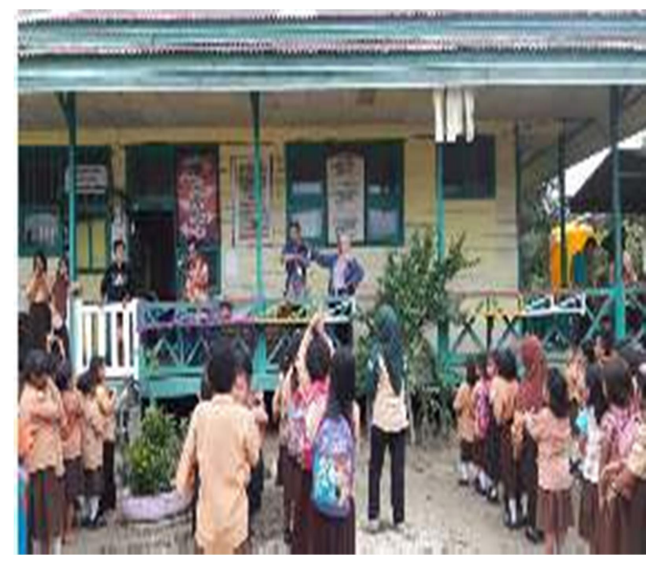

Gambar 3. Sosialisasi Cara Mencuci Tangan yang Bersih dan Benar 


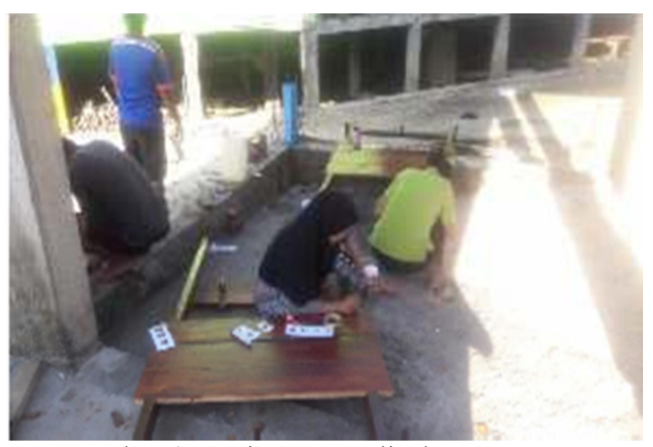

Gambar 4. Kegiatan Menulis dan Mengecat Papan Informasi

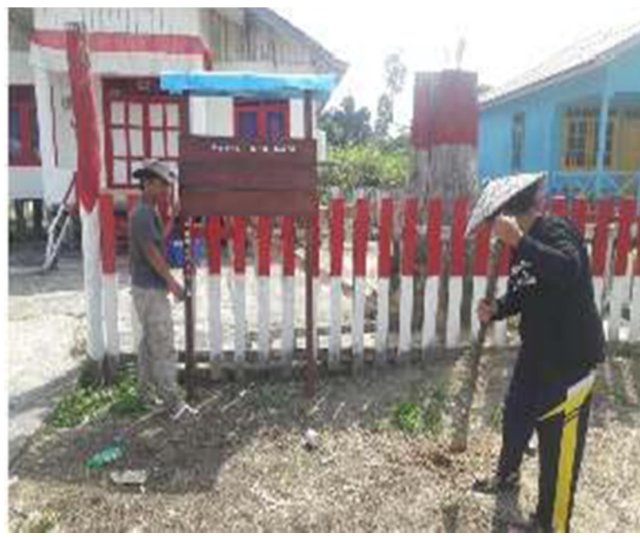

Gambar 5. Proses Pemasangan Papan Informasi Di Kantor Desa

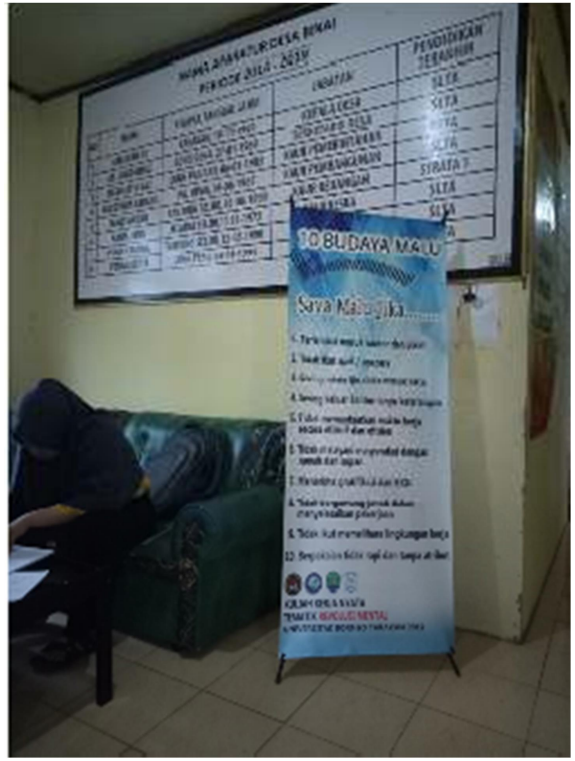

Gambar 6. Pemasangan Banner tentang 10 Budaya Malu Pegawai Kantor Desa

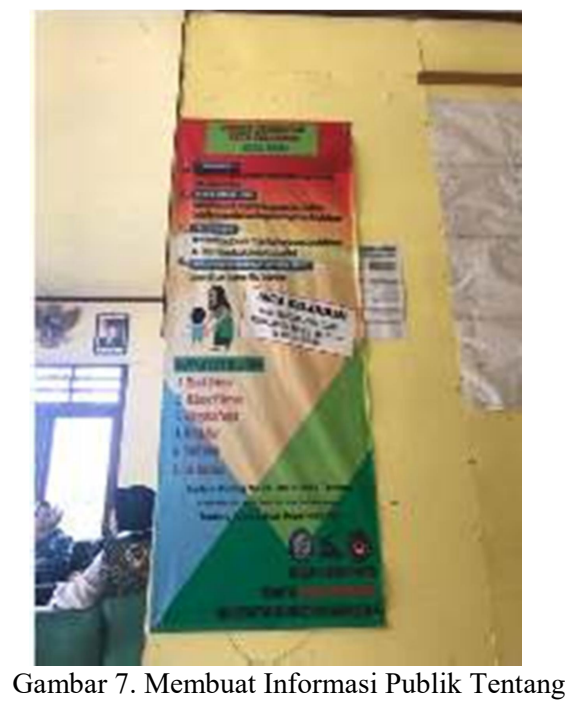
Akta Kelahiran

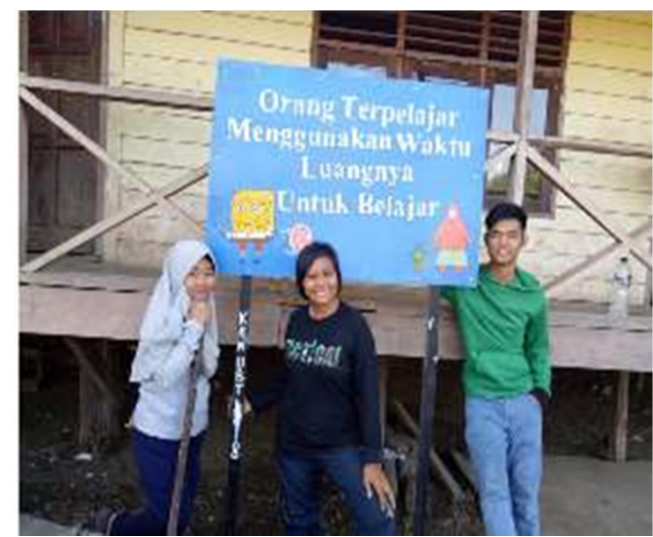

Gambar 8. Pemasngan Slogan Di Sekolah Dasar Negeri 008

\section{PENUTUP}

Kegiatan Program Kemitraan Masyarakat berbasis Revolusi mental dengan Gerakan Indonesia Bersih dan Gerakan Indonesia Tandiri di Desa Binai dan Desa Pura Sajau Kecamatan Tanjung Palas Timur Kabupaten Bulungan berjalan dengan baik. Kegiatan tersebut melibatkan mahasiswa dan masyarakat di desa tersebut. Melalui gerakan Indonesia Bersih Program Kemitraan Masyarakat Revolusi Mental Universitas Borneo Tarakan Menuju 
kesadaran dan kepedulian baik masyarakat maupun pemerintahan desa terhadap kebersihan lingkungan. Sedangkan Gerakan Indonesia Tertib terfokus pada pada pembiasaan perilaku yang tertib dan teratur dengan contoh sederhana menumbuhkan kesadaran berantri dan hidup teratur disiplin serta memiliki rasa malu. Manfaat dari membiasakan dari lingkungan terkecil sampai dengan pemerintah daerah untuk hidup tertib maka akan tercapai perilaku yang tertib dan disiplin.

\section{DAFTAR RUJUKAN}

Katalog Badan Pusat Statistik. 2016. Kabupaten Bulungan Dalam Angka 2016. BPS. Kabupaten Bulungan.

Tim Penyusun RPJMD.2016. Rencana Pembangunan Jangka Menengah Daerah (RJMD). Bappeda. Kabupaten Bulungan. 